\title{
A CASE REPORT ON SUCCESSFUL PREGNANCY AND DELIVERY IN A MEDULLOBLASTOMA PATIENT
}

\author{
Se Hyoun Kwak, MD, In Yang Park, MD, Ji Sun We, MD, Mi Rang Choi, MD, Jong Chul Shin, MD \\ Department of Obstetrics and Gynecology, The Catholic University of Korea School of Medicine, Seoul, Korea
}

\begin{abstract}
Medulloblastomas are rare neoplasms in adults. Medulloblastomas are treated by surgical removal of the tumor followed by radiotherapy. Because craniospinal irradiation can damage the hypothalamic-pituitary axis, uterus, and ovaries, and consequently result in infertility, the probability of pregnancy is quite low. We managed a patient who had undergone resection of a posterior fossa medulloblastoma and received craniospinal irradiation, who conceived spontaneously during follow-up. She was diagnosed with a recurrent medulloblastoma with metastasis to the spine accompanied by headaches and back pain at 26 weeks gestation. Conservative treatment measures were utilized in an effort to prolong the pregnancy. She was delivered by cesarean section due to recurrent seizure activity at 29 weeks plus 3 days gestation. The neonate made favorable progress and was discharged in good condition.
\end{abstract}

Keywords: Medulloblastoma, Recurrence, Metastasis, Pregnancy

뇌종양은 20세 이하 연령에서 2번째로 흔한 악성종양이다. 그 중 수 질아세포종은 소뇌에서 발생하는 악성 배아 종양으로 전체 소아 뇌종양 의 $20 \%$ 와 소아 소뇌 종양의 $40 \%$ 를 차지한다[1,2]. 대개 뇌척수액을 따 라 전이하고 재발이 흔한데, 재발은 주로 치료 후 2 년 이내에 발생하나 성인에서는 치료 후 2년 이후에 재발하는 경우도 있다[3,4]. 원발성 질 환의 치료는 외과적 종양 절제술과 두개척수 방사선 치료를 병행하게 되며 재발한 질환의 경우에는 예후가 좋지 않아 적극적인 치료 방법이 권장되어 수술적 제거 및 항암화학요법이 사용되기도 한다[3,4]. 환자들 은 대부분 가임기 전 연령의 소아 및 청소년으로 두개척수 방사선 치료 로 인해 시상하부-뇌하수체축에 손상을 받아 치료 후에는 희발월경이 나 불임이 되는 경우가 많다[5,6]. 실제로 이러한 환자들에서 임신과 분 만에 성공한 증례는 거의 보고된 바가 없다[7].

저자들은 방사선 치료 후 자연임신이 되었고 종양이 재발되었으나 임 신을 유지하여 이후의 신생아와 산모의 경과가 모두 양호하였던 임신 중 수질아세포종의 재발 및 치료에 관련된 드문 예를 경험하였다. 이에 문헌 고찰과 함께 본 증례를 보고하는 바이다.

\section{증 례}

환 자: 계 $\mathrm{O}$ 애, 32세

산과력: 0-0-0-0

월경력: 초경은 14 세, 월경주기는 30 일 간격으로 규칙적이었고 기간은
4일, 양은 보통이었으며 월경통은 중등도로 있었다. 환자는 19세에 수 질아세포종으로 진단, 수술 및 두개척수부 방사선 치료 받았고 그 후 희 발월경을 보이다가 치료 종결 2년 후부터는 규칙적인 생리주기를 보였 다. 최종 월경일은 2008년 9월 6일이었고, 분만예정일은 2009년 7월 13 일이었다.

가족력: 특이사항 없었다.

과거력: 19세인 1995년에 두통과 경련의 증상이 있어 본원 방문하 여 소뇌의 수질아세포종으로 진단받고, 뇌종양전적출, 후두하개두술 및 두개척수 방사선조사 치료를 시행 받았다. 뇌와 척추부의 방사선 조사(whole brain $3060 \mathrm{cGy} / 17 \mathrm{fx}$, posterior fossa $2340 \mathrm{cGy} / 12 \mathrm{fx}$, spine 3450 cGy/23 fx) 치료를 받은 후 시행한 자기공명 영상(magnetic resonance imaging, MRI)검사에서 종양의 완치를 판정 받았다. 이후 오

Received: 2010.12.15. Revised: 2011. 2.15. Accepted: 2011. 2.24.

Corresponding author: Jong Chul Shin, MD

Department of Obstetrics and Gynecology, Seoul St. Mary's

Hospital, 505 Banpo-dong, Seocho-gu, Seoul 137-701, Korea

Tel: +82-2-2258-6169 Fax: +82-2-595-1549

E-mail: jcshin@catholic.ac.kr

This is an Open Access article distributed under the terms of the Creative Commons Attribution Non-Commercial License (http://creativecommons.org/licenses/ by-nc/3.0/) which permits unrestricted non-commercial use, distribution, and reproduction in any medium, provided the original work is properly cited.

Copyright (๑) 2011. Korean Society of Obstetrics and Gynecology 
른쪽 팔다리의 근력 약화 및 보행 장애와 진전 증상에 대한 대증적 치료 를 하였다.

주 소: 임신 26주 4일로 내원 수일 전부터 약한 허리통증이 있어 진통

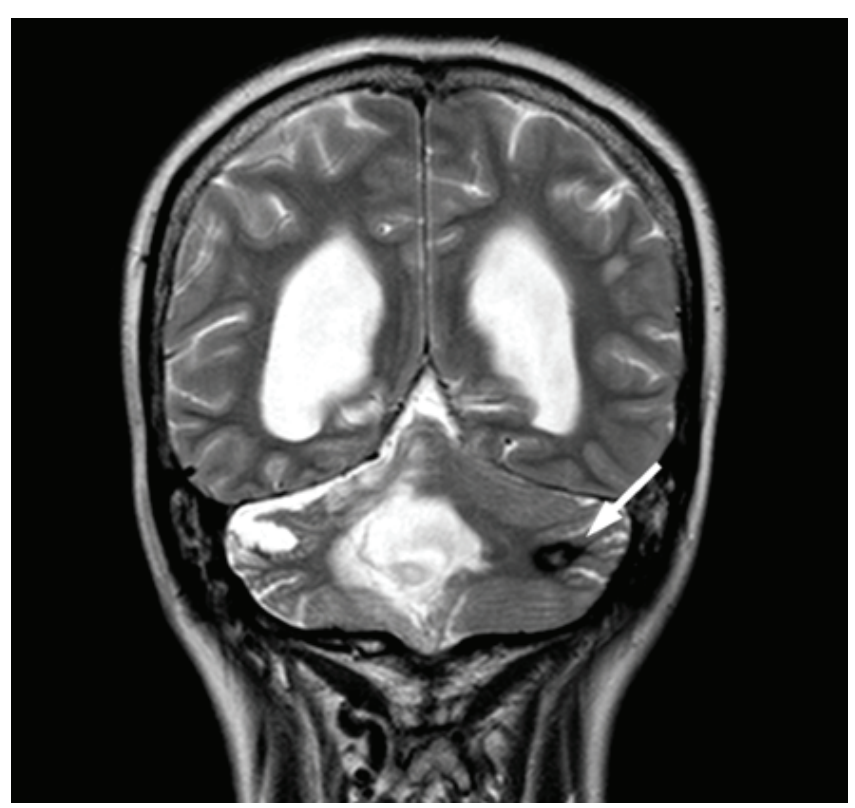

Fig. 1. T2 weighted coronal MR image of brain shows high signal at the bilateral cerebellum and vermis. These findings are old leukoencephalomalatic changes with atrophic changes. Dark signal dot (white arrow) at the left cerebellum is suggested hemangioma.

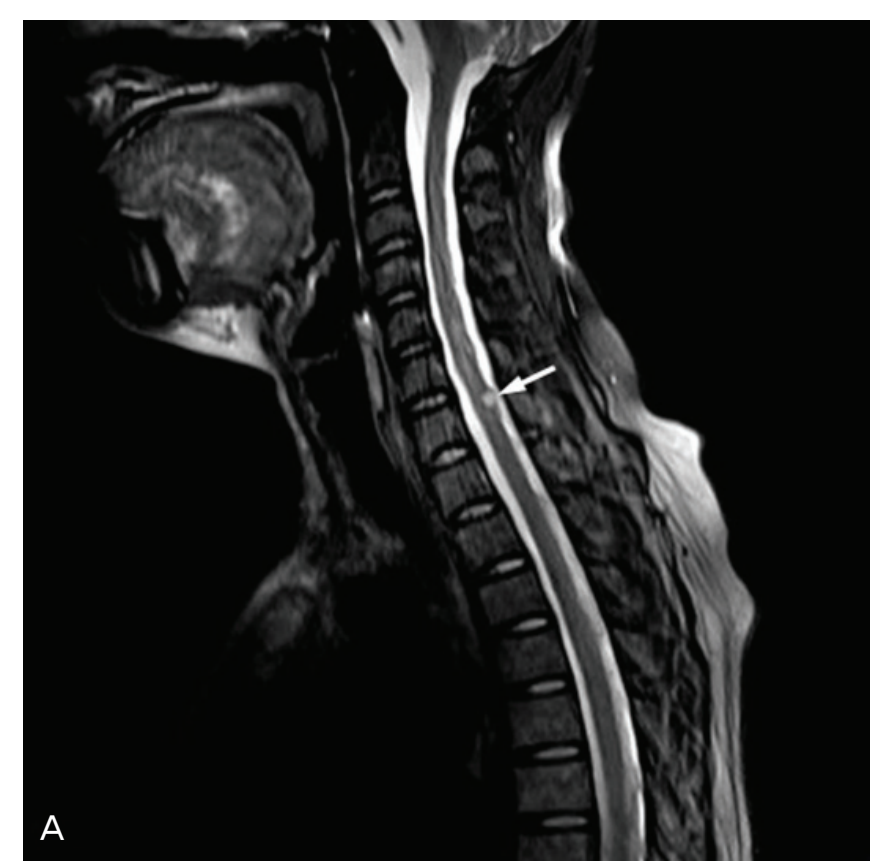

제로 타이레놀을 복용하였으나 허리 통증이 심해지고 심한 두통이 동반 되어 응급실에 내원하였다. 통증의 원인에 대하여 검사하던 중 복통이 발생하여 산부인과 협진이 의뢰되었다.

현병력: 환자는 특이사항 없이 신경외과 외래 추적관찰을 받던 중에 32 세에 자연 임신하여 타 병원 산부인과에서 산전 진찰을 받아왔다. 타 병 원의 산전 진찰 기간 동안 시행한 검사에서 특이 소견 없었으며, 본원 에서 임신 26주 5일에 시행한 초음파 검사 소견에서 자궁 경부 길이는 $4.24 \mathrm{~cm}$ 였고 양두정골 직경 $6.69 \mathrm{~cm}$ (27주 0일), 복부둘레 $21.94 \mathrm{~cm}$ (26주 3일), 대퇴골 길이 $4.88 \mathrm{~cm}$ (26주 3일), 양수지수는 $14.2 \mathrm{~cm}$ 이며 태반과 자궁동맥 혈류 도플러도 특이 소견 없었다. 비수축검사상 태아 심박동은 중등도의 변동성을 보였고 1분 간격으로 $20 \mathrm{~mm} \mathrm{Hg}$ 의 규칙적 인 자궁 수축의 양상을 보였다. 내진상 자궁 경부 개대는 일어나지 않은 상태였고, 생물리학 계수는 10점이었다.

입원 시 진찰소견: 혈압 120/80 mm Hg, 맥박 72회, 호흡 20회, 체온 $36.9^{\circ} \mathrm{C}$ 였으며, 신경학적 검사상 오른쪽 편위 경향(Rt. side falling tendency), 몸통운동실조, 활동 떨림, 양쪽 운동 거리 조절 이상, 오른쪽 공조 운동 보행 장애와 상반 운동 반복 수행 장애에 양성 소견을 보였다.

입원 시 자기공명영상 소견: 경추 7 번, 흉추 9 번 부위에 뇌척수액 파종 성 전이 및 마미증후군 의심되는 소견이 관찰되었다(Figs. 1, 2).

입원 경과: 침상 안정과 수액 요법을 시행하였으나 복통이 지속되고 자 궁 수축 정도가 심해지며 자궁 경부의 길이가 감소되고 자궁 경부가 개 대되는 조기진통 소견 보여 리토드린 투여로 조기진통 억제 치료를 시 행하였다. 두통은 타이레놀과 코데인으로 조절하였다. 조기진통 억제 제로 치료를 시작한 4 일 뒤인 임신 27주 2일에 자궁 수축이 호전되어

Fig. 2. (A) Fat suppressed $T 2$ weighted sagittal MR image of spin shows a small nodular mass (white arrow) with high signal on dorsal portion of spinal cord at C7 level. (B) Multiple lesions (white arrow heads) are also seen along intradural and extramedullary layer on the thoracolumbar spine level. These masses surround and compress spinal cord, and extend along the cauda equina. 


\section{KOREAN JOURNAL OF OBSTETRICS \& GYNECOLOGY}

Se Hyoun Kwak, et al. A case of the pregnancy and delivery in a medulloblastoma patient

리토드린 투여를 중단하였다. 항암 치료와 방사선 치료 등의 신경외과 적 치료는 통증의 조절이 양호하고 뇌압 상승 징후 등 병의 진행이 없 는 상태이므로 신생아 생존율을 높이기 위해 30주까지 임신을 유지하 기로 계획하고 대증적 치료를 유지하였다. 이후 산모는 임신 29주에 허 리 통증과 심한 두통이 다시 발생하였다. 확진을 위한 뇌척수액 세포 검 사를 위한 천자를 고려하였으나 구역, 구토의 증상과 통증의 악화로 뇌 압 상승에 의한 것으로 진단하고 뇌척수액 세포 검사는 시행하지 않고 태아 폐성숙 촉진을 위해 덱사메타손 투여를 시작하였다. 임신 29주 3 일에 전신 경련 반복되어 임신의 유지가 어려워 응급 제왕절개를 시행 하였다. 환자 전신 경련 중에 시행한 태아 심음 청취에는 특이사항이 없 었다. 신생아는 남아 $1.46 \mathrm{~kg}$ 으로 출생 시의 재태 연령인 29주 3일의 $50 \%$ 에 해당되는 적합한 체중이었으며, 아프가(Apgar) 점수는 1분 7점, 5 분 8점이었다. 신생아는 유리질막증 소견을 보여서 인공계면활성제를 2회 투여하였고 이후 경과 양호하여 생후 61일째에 체중 $3.41 \mathrm{~kg}$ 으로 퇴원하였다. 현재는 출생 예정일 기준의 교정 연령 18 개월로 특이사항 없이 성장 발달 중이다.

분만 후 경과: 환자는 제왕절개 수술 후 12일째에 뇌척수액 천자, 26일째 에 2, 3번 요추 후궁 절제술, 41일째에 항암치료(carboplatin, etoposide, ifosfamide, vincristine)를 시행하였고, 이후 경과 양호하였다.

\section{고 찰}

수질아세포종(medulloblastoma)은 소뇌 및 후두와에서 생기는 악 성 뇌종양으로, 천막하 원시신경외배엽종양(primitive neuroectodermal tumor)으로 분류된다. 약 $70 \%$ 정도가 16 세 이하 연령의 소아에서 발생 하며 성인에서의 발생은 드물어 뇌신생물의 $1 \%$ 이하를 차지한다[1,2]. 치료는 종양 절제술과 두개척수 방사선조사 치료를 하는 것이 기본이며 항암치료를 추가로 시행하기도 한다[3,4]. 생존율은 60-70\%에 달하지 만 재발 시에는 예후가 좋지 않은 것으로 알려져 있다[4]. 부적절한 수 술이 이루어진 경우나 뇌척수액, 척수, 천막상부 또는 전신적인 전이가 있을 때에 예후가 나쁘다. 적절한 수술과 방사선 치료가 이루어진 경우 에도 재발이 흔하며, 주로 치료 2 년 이내에 재발하나 성인의 경우에는 치료 2년 이후에 재발하기도 한다[3,4]. 원발 부위의 재발이 가장 흔하 나 10-20\%의 환자에서는 전신적인 전이가 문제가 되고, 항암치료와 방 사선 치료를 함께 받은 환자 군에서 두개척수 축 재발의 빈도가 더 높다 [4]. 본 증례의 산모의 경우도 치료 후 10년 후에 척수 부위에의 전이로 재발한 경우였다.

뇌종양의 방사선 치료에 의한 시상하부나 뇌하수체에 대한 손상은 월 경과 수정 능력에 관련되는 성선자극 호르몬 분비호르몬(gonadotropinreleasing hormone), 난포자극호르몬(follicle-stimulating hormone), 황 체형성호르몬(luteinizing hormone), 난포호르몬(estradiol), 황체호르몬 (progesterone), 유즙분비호르몬(prolactin) 등의 호르몬의 불균형과 내분 비 장애를 일으켜 정상 임신이 어렵다[5,6]. Wo와 Viswanathan [5]은 두 개척수 방사선조사는 시상하부-뇌하수체축의 기능을 파괴하여 직접적
으로 난소기능부전을 유발하거나 자궁에 영향을 미쳐 임신의 유지가 어 렵다고 하였다. 주 발생 연령이 소아인 점을 고려할 때 특히 환자가 여 아인 경우 훗날 생식 능력 문제에 중요한 영향을 미칠 수 있으나 본 증 례와 같이 자연적인 임신과 임신의 유지가 가능할 수 있다.

한편 임신부에서의 뇌종양은 매우 드물고 임신과 관련된 증상이나 자 간전증 및 자간증 등의 증상과 뇌종양의 증상들이 혼동될 수 있어 진단 이 어렵다[2,7]. 본 증례의 경우는 뇌척수계 종양의 과거력이 있어 재발 에 대한 빠른 추정 진단이 가능하였으나, 중추신경계 종양이 산모에게 발생한다면 두통이나 허리통증, 경련 등의 비특이적 증상으로 인하여 다른 질환으로 잘못 진단될 가능성이 크다[8-10]. 진단을 위한 영상학 적 도구 중 computed tomography보다는 MRI가 안전하게 이용될 수 있 는데, 일반적으로 흔히 이용되는 1.5 telsa의 MRI 기기의 자기장 범위는 산모와 태아에 미치는 영향이 거의 없는 것으로 알려져 있으나[11], MRI 조영제로 쓰이는 가돌리늄은 태반을 통과하고 태아의 배설과 재흡수의 과정을 거치므로 반감기를 알 수 없는 위험성을 가지고 있다. 이와 같은 이유로 임신부에게 조영제의 사용이 권장되지 않으나 진단적으로 반드 시 필요한 경우에 제한적으로 사용할 수 있다[11].

치료는 산모와 태아에 미치는 영향을 함께 고려해야 하기 때문에 개 별적인 접근이 필요하다[8-10,12]. 항암 치료, 방사선 치료 및 수술적 치료가 태아에 미치는 영향에 대해서 고려되어야 하고 조기 분만을 하 게 될 경우 미숙아로 인한 문제가 발생하게 된다[13]. 그러나 태아의 성 숙을 위하여 임신을 유지하는 경우는 치료의 지연으로 인하여 산모의 신경학적 합병증 발생의 가능성이 있으며, 드물지만 종양이 태반으로 전이된 예가 보고된 경우도 있다[14,15]. 따라서 치료 방침을 결정할 때 에는 반드시 환자의 상태와 재태 연령이 모두 고려되어야 한다. 신경학 적 증상이 없거나 종양의 크기가 작다면 임신을 유지하고 치료를 지연 시킬 수 있다. 그러나 종괴의 크기가 크거나 뇌부종으로 뇌압이 상승하 고 신경학적 합병증이 심각한 경우는 뇌압과 신경학적 증상을 조절하 며 치료 시작을 위한 임신 종결 시기를 결정해야 한다[8-10]. 분만 방법 은 신경학적 합병증을 고려하여 결정하여야 하는데 정상인에서 뇌 내압 은 $20 \mathrm{~cm} \mathrm{H}_{2} \mathrm{O}$ 이하인데 자연 분만 중의 뇌 내압은 분만 1기에 평균 53 $\mathrm{cm} \mathrm{H}_{2} \mathrm{O}$, 분만 2기에 평균 $70 \mathrm{~cm} \mathrm{H}_{2} \mathrm{O}$ 로 측정된다. 이런 극단적인 뇌 내 압변화는 뇌 내압이 증가되어 있는 환자에서 신경학적 손상이나 뇌탈 출증을 일으킬 수 있기 때문에 분만 진통과 질식분만이 금기가 된다[8]. 그리고 경막외 마취는 우발적 요추천자로 인한 뇌탈출 가능성과 사망의 위험성이 있기 때문에 금기이다[10]. 따라서, 뇌부종 및 뇌 내압 증가에 대한 적절한 처치가 요구되며, 일반적으로 전신마취하의 제왕절개 수술 을 통한 분만이 권유된다[8-10]. 분만 후에는 가능하면 이른 시기의 종 양제거 수술이 권유되며, 태반으로의 전이는 매우 드물고 태아로의 전 이는 거의 보고된 바가 없지만 태반의 조직검사 및 태아의 혈액 내 종양 표지자 검사도 추천된다[14,15]. 본 증례의 경우도 임신을 유지하는 동 안 산전 초음파를 통하여 태반과 태반 및 자궁의 혈류의 흐름의 변화 여 부를 관찰하였고 분만 후 태반 조직검사를 시행하였으나 태반으로의 전 이는 관찰되지 않았다.

수질아세포종 등의 뇌종양으로 가임기나 가임기 전의 여성이 두개척 
수 방사선 치료를 받는 경우 일반적으로 가임력의 저하나 상실을 가져 올 수 있어 자연임신에 대한 기대는 어렵다[5,6]. 그러나 본 증례에서 저 자들은 수질아세포종으로 전뇌척수 방사선 조사 치료 후에도 자연 임신 을 하고 성공적으로 분만한 증례를 경험하였다. 이는 향후 수질아세포종 등 뇌종양 진단을 받고 방사선 치료를 받은 가임기 여성이나 가임기 전 여성의 향후 임신 가능성 등에 대한 예후 설명과 뇌종양이 재발한 임산 부의 치료 방침을 정하는 데 도움이 될 수 있을 것으로 기대하는 바이다.

\section{References}

1. Seok JY, Kim SH, Lee YH, Kwon J, Kim TS. Vimentin and survivin expression rates as prognostic factors in medulloblastoma. Korean J Pathol 2007;41:87-94.

2. Chan AW, Tarbell NJ, Black PM, Louis DN, Frosch MP, Ancukiewicz $\mathrm{M}$, et al. Adult medulloblastoma: prognostic factors and patterns of relapse. Neurosurgery 2000;47:623-31.

3. Fukunaga-Johnson N, Lee JH, Sandler HM, Robertson P, McNeil E, Goldwein JW. Patterns of failure following treatment for medulloblastoma: is it necessary to treat the entire posterior fossa? Int J Radiat Oncol Biol Phys 1998;42:143-6.

4. Friedberg MH, David O, Adelman LS, Heilman CB. Recurrence of medulloblastoma: violation of Collins' law after two decades. Surg Neurol 1997;47:571-4.

5. Wo JY, Viswanathan AN. Impact of radiotherapy on fertility, pregnancy, and neonatal outcomes in female cancer patients. Int J Radiat Oncol Biol Phys 2009;73:1304-12.

6. Pai HH, Thornton A, Katznelson L, Finkelstein DM, Adams JA, Fullerton $B C$, et al. Hypothalamic/pituitary function following high-dose conformal radiotherapy to the base of skull: demon- stration of a dose-effect relationship using dose-volume histogram analysis. Int J Radiat Oncol Biol Phys 2001;49:1079-92.

7. Razak AR, Nasser Q, Morris P, Alcutt D, Grogan L. MedulIoblastoma in two successive pregnancies. J Neurooncol 2005;73:89-90.

8. Stevenson CB, Thompson RC. The clinical management of intracranial neoplasms in pregnancy. Clin Obstet Gynecol 2005:48:24-37.

9. Chaudhuri P, Wallenburg HC. Brain tumors and pregnancy. Presentation of a case and a review of the literature. Eur J Obstet Gynecol Reprod Biol 1980;11:109-14.

10. Tewari KS, Cappuccini F, Asrat T, Flamm BL, Carpenter SE, Disaia PJ, et al. Obstetric emergencies precipitated by malignant brain tumors. Am J Obstet Gynecol 2000;182:1215-21.

11. Shellock FG, Kanal E. Policies, guidelines, and recommendations for MR imaging safety and patient management. SMRI Safety Committee. J Magn Reson Imaging 1991;1:97-101.

12. Choi JU, Yoon KY, Han JM, Jung YA, Rhim CC, Kim SJ, et al. A case of maternal metastatic brain tumor was detected in midtrimester. Korean J Obstet Gynecol 2006;49:2388-93.

13. Park IY, Yi CS, Shin JC, Lee JH, Lee HJ, Kang DH. Proper time of delivery to decrease minor perinatal morbiditles. Korean J Obstet Gynecol 2002;45:373-7.

14. Pollack RN, Pollak M, Rochon L. Pregnancy complicated by medulloblastoma with metastases to the placenta. Obstet Gynecol 1993;81:858-9.

15. Brossard J, Abish S, Bernstein ML, Baruchel S, Kovacs L, Pollack R. Maternal malignancy involving the products of conception: a report of malignant melanoma and medulloblastoma. Am J Pediatr Hematol Oncol 1994;16:380-3.

\section{수질아세포종 환자에서의 성공적 임신과 분만 1 예}

\section{가톨릭대학교 의과대학 산부인과학교실}

곽세현, 박인양, 위지선, 최미랑, 신종철

수질아세포종(medulloblastoma)은 성인에게 매우 드문 질환이다. 치료는 수술적 제거와 방사선 조사가 병행되며, 두개척수 조사 후 시상 하부-뇌하수체축과 자궁, 난소의 손상으로 불임을 유발할 수 있어 임신 가능성이 매우 낮다. 저자들은 수질아세포종으로 뇌수술 및 전뇌 척추 방사선 조사 치료 후에도 자연 임신하였던 환자를 경험하였다. 산모는 임신 26주에 두통과 허리통증의 발생을 동반한 수질아세포종 의 재발 및 척추 전이를 진단 받았으나 임신을 지속하기 위해 보존적 치료를 유지하던 중 반복되는 전신 경련 증상으로 임신 29주 3일에 제왕절개 분만하였고, 신생아의 경과가 양호하여 건강하게 퇴원하였다.

중심단어: 수질아세포종, 재발, 전이, 임신 